\title{
The Phonics Approach in Swedish Children using Cochlear Implants or Hearing Aids: Inspecting Phonological Gain
}

\author{
Cecilia Nakeva von Mentzer ${ }^{{ }^{\star}}$, Björn LyxelI ${ }^{1}$, Birgitta Sahlén ${ }^{2,6}$, Örjan Dahlström ${ }^{1}$, Magnus Lindgren ${ }^{2,4}$, Marianne Ors ${ }^{2}$, Petter Kallioinen $^{5}$ and Inger Uhlén $^{3}$ \\ ${ }^{1}$ Department of Behavioral Sciences and Learning, Swedish Institute for Disability Research, Linköping University, 58183 Linköping, Sweden \\ ${ }^{2}$ Linneaus Centre: Cognition, Communication \& Learning, Lund University, Box 117, 22100 Lund, Sweden
}

${ }^{3}$ Karolinska University Hospital and Karolinska Institutet, Rosenlunds sjukhus, plan 8, Tideliusgatan 12, 11869 Stockholm, Sweden

${ }^{4}$ Department of Psychology, Lund University, Box 117, 22100 Lund, Sweden

${ }^{5}$ Department of Linguistics, Stockholm University, 10691 Stockholm, Sweden

${ }^{6}$ Department of Logopedics, Phoniatrics and Audiology, Lund University Skåne University hospital 22185 Lund, Sweden

*Corresponding author: Cecilia Nakeva von Mentzer, Department of Behavioral Sciences and Learning, Linköping University, Sweden, Tel: +46-13-28 20 60; E-mail: cecilia.nakeva.vonmentzer@neuro.uu.se

Received: August 29, 2014; Accepted: October 04, 2014; Published: October 11, 2014

Copyright: $\odot 2014$ Nakeva von Mentzer C, et al. This is an open-access article distributed under the terms of the Creative Commons Attribution License, which permits unrestricted use, distribution, and reproduction in any medium, provided the original author and source are credited.

\begin{abstract}
The present study investigated cognitive abilities (i.e. Phonological Processing Skills (PhPS), lexical access, complex and visual Working Memory (WM), and letter knowledge) in Deaf and Hard of Hearing children (DHH) 5, 6 and 7 years of age using cochlear implants or hearing aids. Children with Normal Hearing (NH) served as a reference group. All children took part of a computer-assisted intervention with a phonics approach for 4 weeks aimed to support PhPS. The first aim of the study was to examine associations between cognitive abilities and Phonological Processing Skills (PhPS) pre intervention in $\mathrm{DHH}$ and $\mathrm{NH}$ children respectively. The second aim was to examine cognitive predictors of phonological gain post intervention. Finally, the influence of background variables on phonological gain was examined in $\mathrm{NH}$ and $\mathrm{DHH}$ respectively and in $\mathrm{DHH}$ children with weak PhPS particularly. Results showed comparable performance level in $\mathrm{NH}$ and $\mathrm{DHH}$ children on the majority of cognitive tasks, but weaker PhPS and lexical access in the DHH children. A significant association between PhPS and complex WM was only evident in $\mathrm{DHH}$ children. This finding suggests that $\mathrm{DHH}$ recruit more cognitive resources in phonological processing. A phonological representation task was the single predictor of phonological gain in $\mathrm{DHH}$ children. Children with initial weak performance on this task but had letter-naming skills, displayed relatively more phonological gain from the phonics training. Children with difficulties with the phonological representation task were older when diagnosed and had an older age at amplification. Further, these children displayed broader cognitive difficulties, suggesting that reduced access to auditory stimulation may have wide ranging effects on cognitive development.
\end{abstract}

Keywords: Deaf and hard of hearing; Children; Cochlear implants; Hearing aids; Phonological gain; Cognitive abilities

\section{Introduction}

Phonological processing is a central concept in cognitive psychology which is used to refer to mechanisms involved in representing, accessing or manipulating information related to the sound structure of language [1]. Phonological Processing Skills (PhPS) are thus a set of abilities that we use in many different contexts in everyday life. Due to their intimate connection to the sound structure of spoken language, there are many Deaf and Hard of Hearing children (DHH) who struggle to develop them [2-4]. PhPS is further related to the acquisition and use of lexical items as well as to the building and organization of the mental lexicon [5,6], which is especially difficult for DHH children who experience periods of auditory deprivation or distortion [7-12]. Additionally, PhPS are interconnected to the development of phonological decoding, a skill that is challenging to achieve for many profoundly deaf children [13-15]. The importance of PhPS in a vast number of communicative and learning situations makes it important to find efficient intervention methods for many DHH children [16].
In an earlier computer-assisted intervention study on DHH and $\mathrm{NH}$ children [17] we used a global accuracy measure of PhPS, i.e., a phonological composite score, to study the effects of a phonics approach. Results showed that for the whole group of $\mathrm{DHH}$ children, and specifically for children with $\mathrm{CI}$, a lower initial phonological composite score was associated with a larger phonological gain at post intervention. Still left to explore is how phonological gain is related to or could be supported by other cognitive skills in the DHH child, e.g., working memory, lexical access, and specific aspects of phonological processing. To our knowledge only one intervention study has explored this [18]. Several studies of DHH children have shown reduced capacity in certain aspects of cognition, i.e., WM [19-21] PhPS [22-26], and lexical access [11,25,27-29]. Fewer studies have sought to explore how these cognitive abilities relate to the development of PhPS [30]. Another aspect worth considering when studying DHH children's cognitive development is how reduced spectral resolution [31] and less cues of temporal fine structure [32,33] affect how they develop PhPS in different situations, i.e., speech recognition in noise [21,34], and in reaching fine-grained levels of phonological sensitivity [2]. Thus, as Nittrouer et al. reasoned [2] finegrained levels of phonological processing might be difficult to acquire both due to the hearing loss itself, and due to the signal transmitted 
Citation: $\quad$ Nakeva von Mentzer C, Lyxell B, Sahlén B, Dahlström O, Lindgren M, et al. (2014) The Phonics Approach in Swedish Children using Cochlear Implants or Hearing Aids: Inspecting Phonological Gain. Commun Disord Deaf Stud Hearing Aids 2: 117. doi: $10.4172 / 2375-4427.1000117$

Page 2 of 11

through their technical device. This in turn might alter cognitive strategies, e.g., redirecting attention to other important visual clues in the environment, i.e., written symbols, to compensate for coarsegrained perception. This hypothesis also served as a point of departure in the present study. Thus, the aim is to study whether letter knowledge, a skill that reflects an important step in children's cognitive development as they learn to connect a visual symbol with phonological information, explicitly influences PhPS and phonological gain. Further, we want to address the influence of background variables, since many studies that have sought to compare cognitive abilities in children with $\mathrm{HA}$, children with $\mathrm{CI}$, and children with $\mathrm{NH}$ [27-29] report mixed results. This points to the importance of addressing how, for example, age at identification and amplification, influence DHH children's cognitive development [35].

In the present study, children practice phonics by means of a computer-based intervention program called Graphogame [36]. The goal of the intervention is to enhance perceiving and memorizing phonemic sounds, and to connect them fluently to equivalent orthographic stimuli [37]. Lyytinen and colleagues (2007) propose that in a highly consistent orthography where each letter represents its own phoneme, learning to store and retrieve names of concrete visual objects from memory plays a role in both development of phonemic awareness and reading acquisition. The Swedish version of the intervention program emphasizes almost exclusively the transparent relationships between spoken and written language, sometimes labelled phonemic orthography [38]. The measures that are used in the present study are excerpted from a comprehensive cognitive testbattery [25]. They tap into three different levels of phonological processing; lower-level processing i.e., phoneme discrimination in nonwords, or higher-level processing, i.e., decision making about the phonemic structure of a nonword or about real words vs. nonwords. Further phonological output is tapped, by picture-naming and nonword repetition tasks. The cognitive test battery has been developed from three theoretical paradigms; the Working memory model $[39,40]$, the Capacity theory [41], and theories within specific language impairment, SLI [42-46].

The first purpose of the study is to examine working memory capacity, lexical access, PhPS, and letter knowledge in DHH children and in a reference group of NH children. The second purpose is to explore how these cognitive abilities relate to PhPS pre intervention and to phonological gain post intervention. Finally, the aim is to study the associations between background variables and phonological gain.

\section{Material and Methods}

\section{Participants}

The study was approved by the Regional Committee for Medical Research Ethics; Stockholm, Sweden. Written parental informed consent was obtained for all the participants. Nineteen of the children had a severe/profound HL with a Pure Tone Average (PTA) at $70 \mathrm{~dB}$ Hearing Level or more unaided. Eleven had a moderate HL and two had a mild HL (PTA 34). The inclusion criteria for DHH were that they should have a mild, moderate to severe, or profound bilateral SNHL and be full time users of CI and/or HA. They should perform within the normative range on nonverbal intelligence measures. No other disability that could affect their speech, language or cognitive development should be present. They should speak Swedish at preschool or school, but could use another language at home. Deaf and hard of hearing children were recruited from the Audiological clinic at
Karolinska University hospital in Stockholm, from Uppsala University hospital, and from the Audiological clinic at Lund University hospital. Just below forty families accepted the invitation and were given written and spoken information about the study.

Children with $\mathrm{NH}$ of the same age constituted the reference group. The inclusion criterion for the reference group was normal hearing ascertained at the regular hearing screening at 4 years of age and reported by their parents in a written consent form. They should perform within the normative range on nonverbal intelligence measures.They should speak Swedish in their educational setting and have no disability that could affect their speech and language development. Children with $\mathrm{NH}$ were recruited from preschools and schools in and outside the city of Stockholm.Information regarding background variables e.g., cause and degree of HL, use of technical aid, and age at amplification is given in Table 1 (group level) and Appendix (individual level).

\begin{tabular}{|l|l|l|l|}
\hline & Cl & HA & NH \\
\hline Chronological age & $76 \pm 11(58-93)$ & $75 \pm 12(59-91)$ & $77 \pm 12(60-95)$ \\
\hline Age at diagnosis & $11 \pm 12(1-31)$ & $27 \pm 26(0-64)$ & \\
\hline Age at implant & $26 \pm 16(8-67)$ & & \\
\hline Age at HA & & $36 \pm 24(4-79)$ & \\
\hline $\begin{array}{l}\text { Raven's colored } \\
\text { matrices (raw } \\
\text { scores, max 36) }\end{array}$ & $22 \pm 5(12-32)$ & $22 \pm 5(15-31)$ & $25 \pm 6(14-33)$ \\
\hline
\end{tabular}

Table 1: Background variables in months (mean $\pm \mathrm{SD}$, range) and raw scores on Raven's Matrices (mean $\pm s d$, range) for all participants: children with CI $(\mathrm{n}=17)$, children with HA $(\mathrm{n}=15)$, and children with $\mathrm{NH}(\mathrm{N}=16)$. Note: $\mathrm{CI}=$ Cochlear Implants, HA=Hearing Aids, $\mathrm{NH}=$ Normal Hearing.

Tests and their abbreviations analyzed in the present study are presented in Table 2.

\section{Cognitive tests}

Tests were administered via paper; Phoneme test [47], Letter naming [48], and via cards; Letter knowledge [49], as well as by computer by means of the Sound Information Processing System, i.e., SIPS [25]. The SIPS is a computer-based test battery with auditorially and visually presented tasks. The SIPS allows recordings of two measures; accuracy and latency (proportion correct responses and response latency in $\mathrm{ms}$ ) in the nonword discrimination and the phoneme identification task.

Lexical access: The Sentence Completion and Recall task (SCR), from the SIPS [25] was used for two purposes, to assess both complex working memory capacity (described below) and lexical access. To measure lexical access children's spoken answers were categorized in four categories: 1) Expected, 2) Semantically acceptable (within the same category; supra-, side- or sub-ordinated), 3) Semantically deviant (not within the same semantic category), and 4) Others, (no answer, repetition).

Complex working memory: The SCR task [25] was used to assess complex working memory, i.e., the capacity to simultaneously store and process information $[41,50,51]$. The task was to listen to series of sentences with the last word missing and to fill in and memorize the 
Citation: Nakeva von Mentzer C, Lyxell B, Sahlén B, Dahlström O, Lindgren M, et al. (2014) The Phonics Approach in Swedish Children using Cochlear Implants or Hearing Aids: Inspecting Phonological Gain. Commun Disord Deaf Stud Hearing Aids 2: 117. doi: $10.4172 / 2375-4427.1000117$

Page 3 of 11

missing words, e.g., "Crocodiles are green. Tomatoes are ....", and thereafter to repeat the words that were previously filled in. The series of sentences included two, three and four sentences. The results were scored as the total number of correctly reproduced words, with a maximum score of 18 .

\begin{tabular}{|c|c|c|}
\hline Area & Test & Quantification \\
\hline \multirow[t]{4}{*}{ Lexical access } & \multirow[t]{4}{*}{$\begin{array}{l}\text { Sentence completion } \\
\text { and recall, SCR (SIPS, } \\
\text { Wass et al., [25]) }\end{array}$} & $\begin{array}{l}\text { Total number of correctly } \\
\text { completed sentences, } \\
\text { (max=18) }\end{array}$ \\
\hline & & $\begin{array}{l}\text { Semantically accepted } \\
\text { answers, }(\max =18)\end{array}$ \\
\hline & & $\begin{array}{l}\text { Semantically deviant } \\
\text { answers, }(\max =18)\end{array}$ \\
\hline & & Other, $(\max =18)$ \\
\hline $\begin{array}{l}\text { Complex } \quad \text { working } \\
\text { memory }\end{array}$ & $\begin{array}{l}\text { Sentence completion } \\
\text { and recall, SCR (SIPS, } \\
\text { Wass et al., [25]) }\end{array}$ & $\begin{array}{l}\text { Total number of correctly } \\
\text { recalled words ( } \max =18 \text { ) }\end{array}$ \\
\hline Visual working memory & $\begin{array}{l}\text { Visual Matrix (SIPS, } \\
\text { Wass et al., [25]) }\end{array}$ & $\begin{array}{l}\text { Percent correctly } \\
\text { recalled/reproduced } \\
\text { patterns }(\max =8)\end{array}$ \\
\hline \multirow[t]{8}{*}{$\begin{array}{l}\text { Phonological processing } \\
\text { skills }\end{array}$} & \multirow[t]{2}{*}{$\begin{array}{l}\text { Phoneme test (Hellqvist, } \\
{[47] \text { ) }}\end{array}$} & $\begin{array}{l}\text { Percent consonants } \\
\text { correct (pcc) out of } 207 \\
\text { (Midst of Sweden) and } \\
211 \text { (South of Sweden) }\end{array}$ \\
\hline & & $\begin{array}{l}\text { Percent words correct out } \\
\text { of } 72(\text { pwc })^{1}\end{array}$ \\
\hline & \multirow{2}{*}{$\begin{array}{ll}\text { Non-word } & \text { repetition, } \\
\text { NWR (SIPS, Wass et } \\
\text { al., [25]) }\end{array}$} & $\begin{array}{l}\text { Percent non-words out of } \\
24 \text { (pnwo) }\end{array}$ \\
\hline & & $\begin{array}{l}\text { Percent consonants out } \\
\text { of } 120(\mathrm{pcc})^{1}\end{array}$ \\
\hline & $\begin{array}{l}\text { Phonological } \\
\text { representation task } \\
\text { (SIPS,Wass et al., [25]) }\end{array}$ & $\begin{array}{l}\text { Percent correct } \\
\text { responses }^{1}(\max =18)\end{array}$ \\
\hline & $\begin{array}{l}\text { Non-word discrimination } \\
\text { accuracy and latency for } \\
\text { correct responses, ND } \\
\text { (SIPS, Wass et al., [25]) }\end{array}$ & $\begin{array}{ll}\begin{array}{l}\text { Percent } \\
\text { discriminated }\end{array} & \text { correctly } \\
\text { non-words }^{1} & \text { (max }=8) \\
\text { Mean response } & \text { latency } \\
\text { (msec) } & \end{array}$ \\
\hline & \multirow[t]{2}{*}{$\begin{array}{l}\text { Phoneme Identification } \\
\text { accuracy and latency, PI } \\
\text { (SIPS, Wass et al., [25]) }\end{array}$} & $\begin{array}{l}\text { Percent correctly } \\
\text { identified phonemes }{ }^{1} \\
(\max =12)\end{array}$ \\
\hline & & $\begin{array}{l}\text { Mean response latency } \\
\text { (msec) }\end{array}$ \\
\hline \multirow[t]{3}{*}{ Letter knowledge } & $\begin{array}{lr}\begin{array}{l}\text { Lower-case } \\
\text { names-pointing }\end{array} & \text { letter } \\
\text { [49]) } & \end{array}$ & $\begin{array}{l}\text { Percent correct } \\
\text { responses }(\max =26)\end{array}$ \\
\hline & $\begin{array}{lr}\text { Lower-case } & \text { letter } \\
\text { sounds-pointing } & \text { (Clay, } \\
[49]) & \end{array}$ & $\begin{array}{l}\text { Percent correct } \\
\text { responses }(\max =26)\end{array}$ \\
\hline & $\begin{array}{ll}\text { Lower-case } & \text { letter } \\
\text { sounds-naming } & \\
\text { (Frylmark, [48]) } & \end{array}$ & $\begin{array}{l}\text { Percent } \quad \text { correct } \\
\text { responses }(\max =24)\end{array}$ \\
\hline
\end{tabular}

Table 2: Cognitive tests. Note: SIPS=Sound Information Processing System (Wass et al., [25]), ${ }^{1}=$ included in the phonological composite score.
Visual working memory: The Visual Matrix test from the SIPS [25] was used to assess visual working memory [50]. A pattern of filled-in cells in a five by five matrix was displayed on the computer screen for two seconds. Thereafter, the task was to replicate the pattern of filledin cells in an empty matrix. The level of difficulty increased from 1 to 8 filled-in cells. The children received scores for the highest level of difficulty at which they correctly reproduced two out of three test patterns. Maximum score was 8 .

Phonological working memory: A Nonword Repetition test from the SIPS [25] was used to assess phonological working memory $[21,52,53]$. In this task, the children were asked to repeat individual 3-4 syllable nonwords. The nonwords differed in length but were otherwise balanced for segmental and suprasegmental aspects. Children's performance was audio-recorded and performance was scored in two different ways: as Percent Nonwords Correct (pnwc) and as Percent Consonants Correctly (pcc) reproduced.

Output phonology: Output phonology was assessed in the Phoneme-test [47]. In this task a picture with everyday objects was presented to the child. The child was asked to name (orally) the picture that the test leader pointed to. Children's performance was audio recorded. Children's oral naming was scored binary (maximum 72), as Percent Words Correct (pwc), and as Percent Consonants Correct (pcc) (a maximum of 207 was possible for children with a dialect from the Midst of Sweden, and a maximum of 211 for children with a dialect from the south of Sweden). Due to ceiling effects on the Phoneme test (pcc and pwc) for the whole sample of children (pcc; $\mathrm{M}=92, \mathrm{Mdn}=98, \mathrm{pwc} ; \mathrm{M}=81, \mathrm{Mdn}=94$ ) as well as for DHH children (pcc; $M=89, M d n=97$, pwc; $M=74, M d n=89$ ) a bimodal classification was used. Children were classified as having phonological output problems when they scored $<95 \%$ on pcc and $<90 \%$ on pwc. This cutoff was used since some phonemic distinctions are difficult to produce even for children with $\mathrm{NH}$ and typical development at the ages of 5, 6 and 7 years, without being considered as output-phonology problems, e.g., trills, fricatives, and consonant-clusters of three consonants [54]. The bimodal classification (problems yes or no) was only used in the analysis on the whole group of DHH children $(\mathrm{N}=32)$.

Phonological representation: A Phonological representation task from the SIPS [25] was employed to assess how children identified mispronunciations of real words and taps into a range of skills, i.e., the child's representations of words in long-term memory, working memory capacity, inhibitory control, and sensitivity to phonemic structure. First, the child was asked to name a picture. If it was not correctly named, the examiner named the picture. Then five different versions of the word were auditorially presented - one at a time. One version was correct and the other four differed in one phoneme. The child was asked to decide whether the word was correct or not by responding "yes" or "no" after each stimulus. The score was the total number of correctly recognized items. 1 point was given for a correct identification of the right pronunciation among the five, $0.25 \mathrm{p}$ for a correct identification of each version that differed in one phoneme. Maximum score was 18. Due to ceiling effects on this task for the whole sample of children $(M=94, M d n=99)$ and when we analyzed DHH children's performance separately $(M=91, M d n=97)$, a bimodal classification with a strict criterion was used to operationalize whether a child had problems or not. Children were classified as having problems when they scored $<17.75 \mathrm{p}(98,6 \%$ correct); that is more than one erroneous answer on the alternatives where one phoneme differed in the presented word. The bimodal classification (problems yes or no) 
Citation: Nakeva von Mentzer C, Lyxell B, Sahlén B, Dahlström O, Lindgren M, et al. (2014) The Phonics Approach in Swedish Children using Cochlear Implants or Hearing Aids: Inspecting Phonological Gain. Commun Disord Deaf Stud Hearing Aids 2: 117. doi: $10.4172 / 2375-4427.1000117$

Page 4 of 11

was only used in the analysis on the whole group of DHH children $(\mathrm{N}=32)$.

Nonword discrimination accuracy and latency: A Nonword Discrimination task from the SIPS [25] was used to assess discrimination of phonemes and phonological working memory [50]. Accuracy and latency $(\mathrm{ms})$ were recorded. The maximum score was 8 . Nonword discrimination latency is referred to as one of two phonological latency scores in the present study. For a more extensive description of the Nonword discrimination task the reader is adviced to Wass et al. [25] and Nakeva von Mentzer et al. [17].

Phoneme identification accuracy and latency: A Phoneme Identification task from the SIPS [25] was used to assess the ability to identify a phoneme within a nonword and taps into phonological working memory and metalinguistic skills [51]. Accuracy and latency (ms) were recorded. The maximum score was 12. Phoneme Identification latency is referred to as one of two phonological latency scores in the present study. For a more extensive description of the Phoneme identification task the reader is adviced to Wass et al. [25] and Nakeva von Mentzer et al. [17].

Phonological composite score: In order to increase the sensitivity and strength of the various specific phonological processing measures, and to enable a general comparison of the children, a phonological composite score was created [17]. The phonological composite score was calculated by a unit weighted-procedure, i.e., each unit was calculated in percent accurate, and then summarized to a global score. Seven units from five tasks of phonological processing skills presented above constituted the phonological composite score. Phonological latency scores were left out. Items were; 1. Nonword repetition (Percent Nonwords Correct; pnwc), 2. Nonword repetition (Percent Consonants Correct; pcc), 3. Phoneme test (Percent Words Correct; pwc), 4. Phoneme test (pcc), 5. Phonological Representations, 6. Nonword Discrimination, and 7. Phoneme Identification. Pearson's correlation coefficient showed moderate to strong correlations between normally distributed units (Nonword Repetition, pcc, Nonword Discrimination, and Phoneme Identification; $r=.50,-r=.74$, $\mathrm{p}<.01$ for all correlations) as well as moderate to strong correlations between units violating assumptions of normality as tested by Kendall's Tau-b's correlation coefficient (Phonological representations, Nonword Repetition, pnwc, Phoneme-test, pwc and pcc; $\mathrm{r}=.51-.91, \mathrm{p}<.01$ for all correlations), suggesting they measure a similar construct. To enable further analysis at a sub-group level, a median split division of the initial phonological composite score was performed in the $\mathrm{DHH}$ children. $\mathrm{DHH}$ children were categorized as skilled $(>63 \%)$ and less skilled $(<63 \%)$.

The phonological gain score: The gain score was calculated as the alteration in the phonological composite score between post and pre intervention, thus, a higher score indicated a higher phonological gain.

Letter knowledge: Children's letter knowledge was assessed with three lower case letter tasks. Two letter recognition tasks were used to measure letter knowledge of names or sounds [49]. In these tasks, the child was presented cards with four letters in a row. The child was instructed to point to one out of four letters as the experimenter read the name (letter-name task), or the sound (letter-sound task) of the letter aloud. The maximum score was 26.The third task was used to measure letter naming [48]. The child was presented with a chart of letters in six rows. The task was to name each letter as the test leader pointed. The maximum score was 24 . Children's performance was audio-recorded.

\section{Intervention program and setting}

The intervention was accomplished by means of a Swedish version of Graphogame, which is a computer program with a phonics approach developed to support children with reading difficulties[37]. The program delivers structured training on the correspondence between phonemes and graphemes in different backgrounds and formats. It begins by presenting falling balls with letters or letter sequences on the screen. The task for the child is to click on the right ball among others that matches the auditory target, before it reaches the bottom of the screen. Graphogame first introduces the spoken phonemes with their corresponding graphemes, then mono-syllabic words $(\mathrm{CV}, \mathrm{VC})$ and, finally, more complex words (CCV, VCV, VCC, $\mathrm{CVCV}$ ). The program enables individual intervention since it adapts itself to each child's level of performance. An algorithm in the program presents approximately $20 \%$ of the items from the pool of new connections between phonemes and graphemes, yet to be learned, in a way to benefit the player's learning. Progression through the game is controlled so that around $80 \%$ will be correct. The program demonstrates how to blend isolated sounds into syllables and words and, thus, offers basic exercises for spelling [37]. Graphogame has a child friendly design to keep children's motivation high, for example they may choose their own favourite game character, a princess, an animal, or a knight, and after each level of difficulty they are rewarded with tokens presented in another background, for example a castle or a garden.One special game is the ghost-and-ladder game where children make the ghost climb up the ladder when giving correct responses [55-57].

The Swedish version of Graphogame includes 56 levels, categorized in three themes according to the phonological and orthographical complexity of the words. It starts with isolated capital letters and their corresponding sounds, then introduces the lower case letters, advances to one-syllable words with CV (Consonant Vowel) structure (theme 1), proceeds to VC, CVC, VCC and CVCC structures (theme 2), and finally delivers training for up to seven letter words (theme 3 ). The words at theme 3 contain initial consonant clusters as well as words with the first examples of larger grapho-phonemic units, namely the bigraphs: "ng" [n], "sj" [J] and tj [ç].

All participating children were informed to practice ten minutes per day for 4 weeks with the game. They were told to practice in a way that corresponded as closely as possible to their way of normally using a computer. If the DHH children listened through external loudspeakers or through a hearing loop in the normal case, they were instructed to continue to do so when they were practicing. Nonetheless, all children listened through external loudspeakers when practicing. In case the DHH child experienced difficulties to discriminate between voiceless plosives (that is, $\mathrm{p}-\mathrm{t}$ ), the parents were advised to show the difference between the sounds by explicitly articulating that is, showing their mouth movements to the child. Thus, if a DHH child had phonemic knowledge but experienced difficulties to perceive the difference between phonemes should not prevent them from continuing to the next level. The length of the intervention closely resembled other studies using the same program for children at risk for reading problems $[37,55]$. Treatment integrity was accomplished by means of personal and written information, web-sms, e-mail correspondence and phone calls from a Speech Language Pathologist (SLP), i.e. the first author. There was no significant difference regarding playing time. Mean time of practice was 7 minutes per day and total mean playing time was approximately $3 \mathrm{~h} 20 \mathrm{~min}$ ( $\mathrm{DHH} ; \mathrm{M}=204$ minutes, $\mathrm{SD}=53$ $\mathrm{NH} ; \mathrm{M}=201$ minutes, $\mathrm{SD}=55)$. The groups $(\mathrm{DHH}, \mathrm{NH})$ did not differ 
Citation: Nakeva von Mentzer C, Lyxell B, Sahlén B, Dahlström O, Lindgren M, et al. (2014) The Phonics Approach in Swedish Children using Cochlear Implants or Hearing Aids: Inspecting Phonological Gain. Commun Disord Deaf Stud Hearing Aids 2: 117. doi: $10.4172 / 2375-4427.1000117$

Page 5 of 11

significantly on any aspect related to the phonics training; reached levels in the game ( $\mathrm{DHH} ; \mathrm{M}=40, \mathrm{SD}=19, \mathrm{NH} ; \mathrm{M}=48, \mathrm{SD}=11$ ), percent correct when practicing ( $\mathrm{DHH} ; \mathrm{M}=89, \mathrm{SD}=7, \mathrm{NH}=92, \mathrm{SD}=6)$, days of practice (DHH; M=21, SD=5, NH; M=21, SD=6), or occasions of practice (DHH; $\mathrm{M}=23, \mathrm{SD}=4, \mathrm{NH} ; \mathrm{M}=22, \mathrm{SD}=6$ ).

For a more detailed description of the computer-based intervention program and setting the reader is adviced to $[17,36,37,56]$.

\section{Design and procedure}

Forty-two of the children's testing were administered and monitored by a SLP (the first author) with extensive experience of testing DHH children, and included three sessions; 1.Baseline 1 (B1), 2.pre intervention, and 3.post intervention with four weeks in between each session. Test session 2 served to control for maturation and testretest effects. At B1 the children were given three testing options: at home, at school or at the clinic. Pre and post intervention tests were administered in a soundproof room at the Linguistic Department at Stockholm University. Six DHH children were tested at the Humanities Lab at Lund University by another SLP who was thoroughly informed and guided through the test procedure by the first SLP. B1 included eight tests for PhPS and letter knowledge. They were administered at one session with one pause after completing four tests. Duration of the session was approximately 50 minutes. Sessions pre and post intervention included the same 8 tests as at B1 as well as tests for visual and complex working memory and reading. Results regarding intervention effects on the eight tasks for PhPS and letter knowledge are reported in a previous study [17], and for reading in a second study [57]. Children were given one pause after half of the tests. Duration of the sessions at pre and post intervention was approximately 90 minutes. Instructions were presented orally to all children but with support by a sign language interpreter for two DHH children with deaf parents who used sign language at home. With the use of a sign language interpreter the duration of the test session was slightly prolonged. Comfortable presentation level and audition were secured by first asking the child and the parent whether the HA or CI was working properly. Second, the child was asked to listen and tell what he/she heard from two initial sentences in the Sentence Repetition task from the SIPS [25]. The presentation level was adjusted according to the child's answer, i.e., when the child expressed that he/she found it hard to hear or could not repeat the sentence, the volume was increased to a ensure a comfortable audible level for each individual child.

\section{Inter-rater reliability}

Inter-rater reliability between the first author and two SLPs was measured on 16 percent (five children) of the collected data from DHH children for transcriptions on the Nonword Repetition task (pnwc, max 24 and pcc, max 120) and the picture-naming task (pwc and $\mathrm{pcc}$ ). The inter-rater reliability between the SLPs' transcriptions was at least $\mathrm{r}=.828(\mathrm{p}<.001)$.

\section{Design and statistical analyses}

All data reported are from tests at pre and post intervention. Two different group comparisons of children's performances were made by independent samples t-tests for normally distributed data and the Mann-Whitney U-test for non-parametric data pre intervention. First, with children's hearing as between-subject factor (1.NH, 2.DHH), and, secondly, with the initial level of the phonological composite score for
$\mathrm{DHH}$ as a function of a median split (1.phonologically skilled DHH, 2.phonologically less skilled DHH). Pearson's correlation coefficient (in case of skewed data Kendall's Tau-b) was calculated between the phonological composite score pre intervention and cognitive tasks (lexical access, complex and visual WM, phonological latency scores, and letter knowledge). This was conducted in three groups; $1 . \mathrm{NH}$, 2.DHH, and 3.phonologically less skilled DHH children. Following this, a correlation analysis between all cognitive tasks, and the phonological gain score was performed. This was done in three groups; 1) $\mathrm{NH}(\mathrm{N}=16), 2) \mathrm{DHH}(\mathrm{N}=32)$, and 3) phonologically less skilled DHH children $(n=16)$. To examine the total contribution of the factors, the significant correlates were put into a multiple linear regression analysis.

\section{Results}

\section{Descriptive statistics and group comparisons pre intervention}

Comparisons of cognitive abilities between the children with $\mathrm{NH}$ and DHH children revealed significantly lower lexical access scores for expected answers and semantically accepted answers. Further, there were significantly more "other" lexical answers in DHH children. Significantly lower scores were observed in DHH children on two separate measures of the phonological composite score; the Nonword Repetition task (pnwc), and the Phonological representation task. Further, lower scores were evident on one of the letter knowledge tasks, i.e. letter sounds. $\mathrm{NH}$ and $\mathrm{DHH}$ children performed at comparable levels on all other measures; semantically deviant lexical access scores, complex and visual working memory, phonological latency scores and letter knowledge. For detailed group comparisons pre intervention the reader is referred to Table 3.

The same comparisons for cognitive variables and age (not included in the table) were performed between phonologically skilled/less skilled DHH children. The analysis showed a significantly higher performance level in phonologically skilled DHH children on the majority of cognitive variables; i.e. lexical access (expected answers), complex and visual working memory, and letter knowledge. Three aspects of lexical access (semantically acceptable, semantically deviant and others) and phoneme identification latency and age( 80 vs. 72 months) did not differ significantly between the groups. Effect sizes in group comparisons between phonologically skilled/less skilled children are presented in Table 3.

\section{Correlation analysis - phonological composite score}

Correlations (Pearson's r, Kendall's Tau-b) were calculated in order to examine the relationship between cognitive abilities; phonological latency scores (not included in the phonological composite score), lexical access, complex and visual WM, letter knowledge, non-verbal intelligence, age, and the phonological composite score for all children (NH and $\mathrm{DHH})$. The procedure was repeated for phonologically less skilled DHH children $(n=16)$. In $\mathrm{NH}$ children the following cognitive variables were significantly correlated with the phonological composite score; lexical access - expected words ( $\mathrm{r}=.60, \mathrm{p}<.05)$, nonword discrimination latency $(\mathrm{r}=-.51, \mathrm{p}<.05)$, and age $(\mathrm{r}=.63, \mathrm{p}<$. 01 ). For the whole group of DHH children the following cognitive variables were significantly correlated with the phonological composite score; lexical access - expected words $(\mathrm{r}=.72, \mathrm{p}<.01)$, lexical access - semantically deviant words $(\mathrm{r}=-.36, \mathrm{p}<.05)$, lexical access - 
Citation: Nakeva von Mentzer C, Lyxell B, Sahlén B, Dahlström O, Lindgren M, et al. (2014) The Phonics Approach in Swedish Children using Cochlear Implants or Hearing Aids: Inspecting Phonological Gain. Commun Disord Deaf Stud Hearing Aids 2: 117. doi: $10.4172 / 2375-4427.1000117$

Page 6 of 11

other words $(\mathrm{r}=-.67, \mathrm{p}<.01)$, nonword discrimination latency $(\mathrm{r}=-.49$, $\mathrm{p}<.01)$, letter sounds $(\mathrm{r}=.29, \mathrm{p}<.05)$, letter names $(\mathrm{r}=.34, \mathrm{p}<.05)$, and complex working memory $(\mathrm{r}=.64, \mathrm{p}<.01)$. For phonologically less skilled DHH children the following cognitive variables were significantly correlated with the phonological composite score; lexical access - expected words $(\mathrm{r}=.72, \mathrm{p}<.01)$, lexical access - other words $(\mathrm{r}=-.70, \mathrm{p}<.01)$, and letter naming $(\mathrm{r}=-.53, \mathrm{p}<.05)$, see Table 4 .

\begin{tabular}{|c|c|c|c|c|c|c|c|}
\hline & Children with $\mathrm{NH}$ & DHH children & $\mathbf{p}$ & $\begin{array}{l}\text { Phonologically } \\
\text { skilled DHH }\end{array}$ & $\begin{array}{l}\text { Phonologically less } \\
\text { skilled DHH }\end{array}$ & p & $\begin{array}{l}\text { Effect size, } \\
r\end{array}$ \\
\hline \multicolumn{8}{|c|}{ Lexical access, SCR (raw scores, $\max 18$ ) } \\
\hline Expected answers & $15.0 \pm 1.6(11-17)$ & $11.0 \pm 5.8(0-18)$ & .035 & $14.0 \pm 3.5(6-18)$ & $9 \pm 6.6(0-16)$ & .007 & .47 \\
\hline Semantically acceptable ${ }^{1}$ & $1.6 \pm 1.1(0-3)$ & $.7 \pm 1.0(0-4)$ & .011 & $.6 \pm .7(0-2)$ & $.9 \pm 1.2(0-4)$ & .495 & \\
\hline Semantically deviant ${ }^{2}$ & $.3 \pm .5(0-1)$ & $1.3 \pm 2.4(0-11)$ & .117 & $.6 \pm 1.1(0-4)$ & $2.1 \pm 3.2(0-11)$ & .082 & \\
\hline Other ${ }^{1,2}$ & $1.5 \pm 1.2(0-4)$ & $4.6 \pm 5.0(0-18)$ & .018 & $2.9 \pm 2.5(0-9)$ & $6.5 \pm 6.2(0-18)$ & .042 & .37 \\
\hline \multicolumn{8}{|c|}{ Complex working memory (raw scores) } \\
\hline SCR, recalled words ${ }^{2}$ & $7.1 \pm 4.2(0-16)$ & $5.6 \pm 3.5(0-13)$ & .221 & $7.6 \pm 2.9(0-13)$ & $3.7 \pm 2.9(0-11)$ & .001 & .56 \\
\hline \multicolumn{8}{|l|}{ Visual working memory (\%) } \\
\hline Visual Matrix ${ }^{2}$ & $38.0 \pm 16.1(13-75)$ & $32.0 \pm 13.2(0-75)$ & .150 & $37.0 \pm 13.3(25-75)$ & $27 \pm 11.4(0-50)$ & .032 & .39 \\
\hline \multicolumn{8}{|l|}{ Phonological processing ${ }^{3}$} \\
\hline Phonological composite score $(\%)^{1,2}$ & $85 \pm 8.8(66-96)$ & $63.0 \pm 14.9(27-87)$ & .000 & $74.0 \pm 6.2(64-87)$ & $53.0 \pm 13.6(27-69)$ & .000 & 71 \\
\hline Phonological representation $(\%)^{1,2}$ & $99.7 \pm .80(97-100)$ & $91.3 \pm 10.7(57-100)$ & .006 & $96.7 \pm 4.5(82-99)$ & $86.0 \pm 14.1(57-100)$ & .007 & .47 \\
\hline Non-word repetition (pnwc) $)^{1,2}$ & $53.0 \pm 18.2(12-80)$ & $7.0 \pm 10.1(0-46)$ & .000 & $13.0 \pm 11.4(0-46)$ & $2.0 \pm 3.0(0-8)$ & .000 & .58 \\
\hline Non-word discrimination (ms) $)^{1,2}$ & $3.6 \pm .34(3.1-4.4)$ & $3.8 \pm .36(3.0-4.9)$ & .067 & $3.6 \pm .31(3.0-4.4)$ & $3.9 \pm .37(3.3-4.9)$ & .030 & .39 \\
\hline Phoneme Identification (ms) & $3.8 \pm 1.1(.40-5.5)$ & $3.9 \pm 1.3(.02-6.9)$ & .160 & $3.6 \pm 1.1(.02-4.8)$ & $4.0 \pm 1.9(1.1-6.9)$ & .504 & \\
\hline \multicolumn{8}{|l|}{ Letter knowledge } \\
\hline Letter sounds $(\%)^{1,2}$ & $93.0 \pm 12.8(54-100)$ & $84.0 \pm 22.0(23-100)$ & .119 & $94.0 \pm 14.9(38-100)$ & $74.0 \pm 23.8(23-100)$ & .008 & .46 \\
\hline Letter names $(\%)^{2}$ & $95.0 \pm 7.4(77-100)$ & $86.0 \pm 20.4(31-100)$ & .187 & $97.0 \pm 9.6(62-100)$ & $75.0 \pm 22.4(31-100)$ & .008 & .67 \\
\hline Letter naming $(\%)^{2}$ & $82.0 \pm 19.0(42-100)$ & $71.0 \pm 30.1(8-100)$ & .186 & $85.0 \pm 22.2(25-100)$ & $57.0 \pm 31.3(8-100)$ & .008 & .46 \\
\hline
\end{tabular}

Table 3: Cognitive variables and letter knowledge scores pre intervention (mean \pm sd, range) for children with $\mathrm{NH}(\mathrm{N}=16)$, $\mathrm{D} / \mathrm{HH}$ children $(\mathrm{N}=32)$, Phonologically skilled DHH $(\mathrm{n}=16)$, and Phonologically less skilled $\mathrm{DHH}(\mathrm{n}=16)$. Note: $\mathrm{NH}=\mathrm{Normal}$ Hearing, $\mathrm{DHH}=\mathrm{Deaf}$ and Hard of Hearing, SCR=Sentence Completion and Recall, pnwc=Percent Nonwords Correct, ${ }^{1}=$ non-parametric data for $\mathrm{NH}$ and $\mathrm{DHH}$ children $(\mathrm{N}=48)$, differences between the groups were analyzed with the Mann-Whitney U-test, ${ }^{2}=$ non-parametric data for phonologically skilled/less skilled DHH children, differences between the groups were analyzed with the Mann-Whitney U-test, ${ }^{3}=$ for detailed results regarding all units of the phonological composite score the reader is referred to Nakeva von Mentzer et al. [17].

\section{Correlation analysis - phonological gain score}

Correlations were computed in order to examine how all measured cognitive variables were associated with the phonological gain score from pre to post intervention. Variables constituting the phonological composite score were included in this second correlation analysis. Three variables had a significant correlation with the phonological gain score for $\mathrm{NH}$ children; lexical access - expected words $(\mathrm{r}=-.58, \mathrm{p}<$. $05)$, lexical access - other words $(\mathrm{r}=.67, \mathrm{p}<.01)$, and letter sounds $(\mathrm{r}=$. $54, \mathrm{p}<.05)$. In the correlation analysis for the whole group of $\mathrm{DHH}$ children, five variables were significantly correlated with the phonological gain score; these were two aspects of lexical access i.e., expected words $(\mathrm{r}=-.36, \mathrm{p}<.05)$ and other words $(\mathrm{r}=.40, \mathrm{p}<.05)$, nonword repetition $(\mathrm{pcc}),(\mathrm{r}=-.37, \mathrm{p}<.05)$, phonological representation (problems yes or no; $\mathrm{r}=-.58, \mathrm{p}<.01$ ), and nonword discrimination accuracy $(\mathrm{r}=-.42, \mathrm{p}<.05)$. For phonologically less skilled DHH children $(n=16)$, seven variables were significantly correlated with the phonological gain score: nonword repetition ( $\mathrm{pcc})(\mathrm{r}=-.55, \mathrm{p}<.05)$, output phonology (pcc) $(\mathrm{r}=-.51, \mathrm{p}<.05)$, phonological representation $(\mathrm{r}=-.65, \mathrm{p}<.01)$, nonword discrimination accuracy $(\mathrm{r}=-.54, \mathrm{p}<.05)$ and all aspects of letter knowledge (letter sounds; $\mathrm{r}=.51, \mathrm{p}<.05$, letter names $\mathrm{r}=.40, \mathrm{p}<.05$, and letter naming; $\mathrm{r}=.62, \mathrm{p}<.05$ ), see Table 5 .

To further examine the predictive strength of the relationships between children's cognitive skills and the phonological gain score, multiple linear regression analyses were conducted in all three groups. The dependent variable was the phonological gain score in all multiple linear regression analyses. In the NH group (1) lexical access - other words and (2) letter sound knowledge were entered as independent variables. After backward elimination of non-significant variables ( $\mathrm{p}>$. 
Citation: $\quad$ Nakeva von Mentzer C, Lyxell B, Sahlén B, Dahlström O, Lindgren M, et al. (2014) The Phonics Approach in Swedish Children using Cochlear Implants or Hearing Aids: Inspecting Phonological Gain. Commun Disord Deaf Stud Hearing Aids 2: 117. doi: $10.4172 / 2375-4427.1000117$

Page 7 of 11

$05)$ a model with only lexical access remained as a significant predictor $\left(\mathrm{F}(1,14)=11.36, \mathrm{p}=.005\right.$, adjusted $\left.\mathrm{R}^{2}=.41\right)$. The Beta coefficient was .67.

\begin{tabular}{|l|l|l|l|}
\hline & NH & DHH & $\begin{array}{l}\text { DHH, } \\
\text { phonologically } \\
\text { less skilled }\end{array}$ \\
\hline 1. Phonological composite score & 1.0 & 1.0 & 1.0 \\
\hline 2. Lexical access; expected answers & $.60^{*}$ & $.72^{* *}$ & $.72^{* *}$ \\
\hline 3. Lexical access; semantically acceptable ${ }^{2}$ & -.47 & .04 & .22 \\
\hline 4. Lexical access; semantically deviant ${ }^{1,2}$ & -.04 & $-.31^{*}$ & -.19 \\
\hline 5. Lexical access; other & -.35 & $-.67^{* *}$ & $-.70^{* *}$ \\
\hline 6. Complex WM & .49 & $.64^{* *}$ & .42 \\
\hline 7. Visual WM ${ }^{2}$ & .28 & .23 & -.13 \\
\hline 8. Nonword discrimination (latency) & $-.51^{*}$ & $-.49^{* *}$ & -.26 \\
\hline 9. Phoneme Identification (latency) & .24 & .08 & .23 \\
\hline 10. Letter knowledge - sounds ${ }^{2}$ & -.14 & $.29^{*}$ & -.29 \\
\hline 11. Letter knowledge - names ${ }^{2}$ & -.10 & $.34^{*}$ & -.15 \\
\hline 12. Letter knowledge - naming & .08 & .12 & $-.53^{*}$ \\
\hline 13. Nonverbal intelligence - raw scores & .28 & .05 & .11 \\
\hline 14. Age & .26 & -.07 \\
\hline
\end{tabular}

Table 4: Correlation analysis between the phonological composite score and cognitive measures obtained pre intervention. Children with $\mathrm{NH}(\mathrm{N}=16), \mathrm{DHH}$ children $(\mathrm{N}=32)$, and phonologically less skilled $\mathrm{DHH}$ children $(\mathrm{n}=16)$. Note: $\mathrm{NH}=$ Normal Hearing, DHH=Deaf and Hard of Hearing, WM=Working Memory, pnwc=Percent Nonwords Correct, pcc $=$ Percent Consonants Correct, pwc $=$ Percent Words Correct, ${ }^{1}=$ non-parametric data for $\mathrm{NH}$ children, ${ }^{2}=$ non-parametric data for $\mathrm{DHH}$ children, ${ }^{3}=$ non-parametric data for $\mathrm{DHH}$ less phonologically skilled children; Kendall's Tau-b correlation coefficient. ${ }^{*} \mathrm{p}<.05,{ }^{* *} \mathrm{p}<.01$.

For the group of all DHH children, five variables were significantly correlated with the phonological gain score. To fit the sample size $(\mathrm{N}=32)$, only the four variables with the highest level of significance were put into the regression analyses; (1) phonological representation (problems yes or no; see method section), (2) nonword discrimination accuracy, (3) nonword repetition (pcc), and (4) lexical access - other answers. After backward elimination of non-significant variables ( $\mathrm{p}>$. 05) a model with only phonological representation remained as a significant predictor $\left(\mathrm{F}(1,28)=11.96, \mathrm{p}=.002\right.$, adjusted $\left.\mathrm{R}^{2}=.27\right)$. The Beta coefficient was .54 .

For phonologically less skilled DHH children (1) phonological representations and (2) letter naming were entered as independent variables. After backward elimination of non-significant variables $(\mathrm{p}>$. $05)$ a model with only phonological representation remained as a significant predictor $\left(\mathrm{F}(1,13)=10.43, \mathrm{p}=.005\right.$, adjusted $\left.\mathrm{R}^{2}=.45\right)$. The Beta coefficient was - .65 .

\section{Background variables related to difficulties with the Phonological representation task}

Nineteen DHH children (59\%) proved to have difficulties with the Phonological representation task. Six of these children used bilateral CI, five used CI and HA, and eight used bilateral HA. For children with bilateral CI the following background variables significantly distinguished those who had difficulties with the Phonological representation task: age at diagnosis $\mathrm{F}(1,9)=8.86, \mathrm{p}<.05$, age at implant $\mathrm{F}(1,9)=11.94, \mathrm{p}<.01$ and time with $\mathrm{CI} F(1,9)=8.14, \mathrm{p}<.05$. Children with CI who had difficulties with the Phonological representation task were significantly older when diagnosed as well as when implanted and had shorter time with CI. The same pattern was observed in children with $\mathrm{CI}$ and $\mathrm{HA}$, and children with $\mathrm{HA}$ although no significant difference was evident (Table 6).

\begin{tabular}{|c|c|c|c|}
\hline & NH & DHH & $\begin{array}{l}\text { DHH, } \\
\text { phonologically } \\
\text { less skilled }\end{array}$ \\
\hline 1. Phonological gain score & 1.0 & 1.0 & 1.0 \\
\hline 2. Lexical access; expected answers & $-.58^{*}$ & $-.36^{*}$ & -.43 \\
\hline 3. Lexical access; semantically acceptable ${ }^{2}$ & .11 & -.01 & .07 \\
\hline 4. Lexical access; semantically deviant ${ }^{1,2}$ & .05 & .04 & .04 \\
\hline 5. Lexical access; other & $.67^{* *}$ & $.40^{*}$ & .42 \\
\hline 6. Complex working memory & .03 & -.26 & .03 \\
\hline 7. Visual working memory ${ }^{2}$ & -.34 & -.00 & .12 \\
\hline 8. Nonword repetition (pnwc) & -.23 & -.29 & -.17 \\
\hline 9. Nonword repetition (pcc) & -.37 & $-.37^{*}$ & $-.55^{*}$ \\
\hline 10. Output phonology (pwc) & .20 & -.34 & -.44 \\
\hline 11. Output phonology (pcc) & .21 & -.38 & $-.51^{*}$ \\
\hline 12. Phonological representation & -.10 & $-.58^{* *}$ & $-.65^{* *}$ \\
\hline 13. Nonword discrimination (accuracy) & -.24 & $-.42^{*}$ & $-.54^{*}$ \\
\hline 14. Nonword discrimination (latency) & -.23 & -.32 & .24 \\
\hline 15. Phoneme Identification (accuracy) & -.49 & -.29 & -.12 \\
\hline 16. Phoneme Identification (latency) & -.23 & -.31 & -.38 \\
\hline 17. Letter knowledge - sounds $^{2}$ & $.54^{*}$ & .12 & $.51^{*}$ \\
\hline 18. Letter knowledge - names ${ }^{2}$ & .32 & .06 & $.40^{*}$ \\
\hline 19. Letter knowledge - naming & .21 & .04 & $.62^{*}$ \\
\hline 20. Nonverbal intelligence - raw scores & .04 & .03 & .06 \\
\hline 21. Age & .01 & -.30 & -.01 \\
\hline
\end{tabular}

Table 5: Correlation analysis between the phonological gain-score and all cognitive measures obtained pre intervention. Children with $\mathrm{NH}$ $(\mathrm{N}=16), \mathrm{DHH}$ children $(\mathrm{N}=32)$ and phonologically less skilled $\mathrm{DHH}$ children $(\mathrm{n}=16)$. Note: $\mathrm{NH}=$ Normal Hearing, $\mathrm{DHH}=$ Deaf and Hard of Hearing, pnwc $=$ Percent Nonwords Correct, $\mathrm{pcc}=$ Percent Consonants Correct, pwc $=$ Percent Words Correct, ${ }^{1}=$ non-parametric data for $\mathrm{NH}$ children, ${ }^{2}=$ non-parametric data for $\mathrm{DHH}$ children, ${ }^{3}=$ non-parametric 
Citation: Nakeva von Mentzer C, Lyxell B, Sahlén B, Dahlström O, Lindgren M, et al. (2014) The Phonics Approach in Swedish Children using Cochlear Implants or Hearing Aids: Inspecting Phonological Gain. Commun Disord Deaf Stud Hearing Aids 2: 117. doi: $10.4172 / 2375-4427.1000117$

Page 8 of 11

data for DHH less phonologically skilled children; Kendall's Tau-b correlation coefficient. ${ }^{*} \mathrm{p}<.05,{ }^{* *} \mathrm{p}<.01$.

\begin{tabular}{|c|c|c|c|c|c|c|}
\hline & $\mathrm{Cl}+(n=5)$ & $\mathrm{Cl}-(n=6)$ & $\begin{array}{l}\mathrm{Cl} / \mathrm{HA}+ \\
(\mathrm{n}=1)\end{array}$ & $\mathrm{Cl} / \mathrm{HA}-(\mathrm{n}=5)$ & $H A+(n=7)$ & HA - $(n=8)$ \\
\hline Chronological age & $83.0 \pm 11.7(67-93)$ & $74.0 \pm 10.2(59-87)$ & 64.0 & $75 \pm 9.8(58-82)$ & $77.3 \pm 13.8(60-92)$ & $74.0 \pm 10.4(61-89)$ \\
\hline Age at diagnosis & $5.8 \pm 3.9(1-9)$ & $14.7 \pm 6.7(2-19)^{*}$ & 1.0 & $17.2 \pm 12.0(1-31)$ & $20.0 \pm 23.0(1-53)$ & $33.1 \pm 27.5(0-64)$ \\
\hline Age at implant & $11.2 \pm 1.9(8-13)$ & $26.7 \pm 8.5(19-39)^{*}$ & 23.0 & $40.0 \pm 21.1(15-67)$ & $\mathrm{N} / \mathrm{A}$ & $\mathrm{N} / \mathrm{A}$ \\
\hline Age at $\mathrm{HA}$ & $N / A$ & N/A & 14.0 & $30.0 \pm 17.7(10-58)$ & $31.6 \pm 18.4(8-54)$ & $39.8 \pm 28.8(4-79)$ \\
\hline $\begin{array}{l}\text { Raven's colored } \\
\text { matrices (max } 36 p \text { ) }\end{array}$ & $18.6 \pm 4.3(12-23)$ & $22.5 \pm 3.2(19-26)$ & 21.0 & $26.0 \pm 5.9(19-32)$ & $23.0 \pm 6.5(15-31)$ & $22.1 \pm 3.9(16-29)$ \\
\hline
\end{tabular}

Table 6: Background variables in months (mean $\pm \mathrm{SD}$, range) and raw scores on Raven's Matrices (mean \pm sd, range) for DHH participants according to their performance on the Phonological representation task (max=18 p). Note: CI=Cochlear Implants, CI/HA=CI and $\mathrm{HA}$, $\mathrm{HA}=$ Hearing Aids, $\mathrm{NH}=$ Normal Hearing, $+=\geq 17.75 \mathrm{p}$ on the Phonological representation task, $-=<17.75 \mathrm{p}$ on the Phonological representation task, N/A=Not Applicable, ${ }^{*}=\mathrm{p}<.05$.

\section{Discussion}

The purpose of the present study was to examine cognitive abilities in DHH children with CI, HA, or a combination of both and in a reference group of $\mathrm{NH}$ children. We specifically studied Working Memory (WM) and lexical access in relation to Phonological Processing Skills (PhPS) pre intervention and to phonological gain post intervention.

\section{Working memory capacity and other measures pre intervention}

Results showed that $\mathrm{NH}$ children outperformed DHH children on the task of lexical access and on the majority of the phonological processing tasks. Equal performance was observed on complex and visual WM as well as on two out of three tasks of letter knowledge. The less efficient lexical access of DHH may have several reasons. First, it may reflect a less developed semantic network related to a reduced auditory stimulation during critical developmental periods in the DHH child's life $[7,8,10-12]$. This probably leaves the DHH child with a poorer lexical network (fewer lexical representations and weaker links between them) in long-term memory. This in turn will most probably affect their verbal processing speed as reported by Pisoni \& Cleary [30]. Second, as the DHH child needs to develop his/her language with a distorted auditory signal, both due to the hearing loss itself and due to limitations of their technical device [2], representations become less phonologically specified, lexically as well as sub-lexically $[6,7,59]$.

As the present results demonstrate, there is a high degree of heterogeneity within DHH children's PhPS. This was particularly evident when we divided the sample according to their initial phonological composite scores and when we examined children's performance on the task of Phonological representation. In line with previous studies our results implicated concordantly that background variables such as age at diagnosis and age at amplification $[35,60,61]$ are closely intertwined with the development of PhPS.

Consistent with previous studies [10,25], similar performance levels were evident for complex as well as for visual working memory in $\mathrm{NH}$ and the whole group of DHH children. This was not apparent for DHH with weak initial PhPS. Thus, beyond weaker PhPS these children also exhibited more limited complex and visual working memory capacity. When we expected background variables a clear pattern appeared. The children with weak PhPS had not benefitted from early auditory experience to the same extent as the $\mathrm{DHH}$ children who were more phonologically skilled. Thus, it may be that reduced auditory access to auditory experience may have had downstream effects on broader fundamental neurocognitive processes for these children [61].

The final group comparison regarding letter knowledge revealed comparable performance levels on two out of three tasks in the $\mathrm{DHH}$ children as to those in the NH children. The lower performance level in letter sounds appeared to be linked to children with HA [17). In the less phonologically skilled $\mathrm{DHH}$ children there were significantly lower scores on all three tasks. These results points to the importance of introducing letters early on in education for all DHH children. Further, it stresses the need to make educators and policymakers aware of the importance to see to that not only children with CI, but also children with HA reach important developmental milestones.

\section{Relations between cognitive abilities and phonological processing skills pre intervention}

A mixed pattern occurred when we examined the relationship between cognitive performance and the phonological composite score in $\mathrm{DHH}$ and $\mathrm{NH}$ children. Positive and significant correlations were observed between lexical access and the phonological composite score for both $\mathrm{NH}$ and $\mathrm{DHH}$. Thus, the close relation between the lexical representations and PhPS corroborates the results in several other studies $[6,7,9]$. Short latency times in the Nonword Discrimination task were also positively and significantly correlated with the phonological composite score for $\mathrm{NH}$ and DHH children, but not if we examined phonologically less skilled DHH children separately. Accordingly, children who quickly perceived consonantal phonemic differences had an advantage when performing several of the tasks that constituted the phonological composite score [25].

For DHH children, complex working memory was most strongly correlated with the phonological composite score, suggesting broader use of cognitive resources in phonological processing in these children. For children with $\mathrm{NH}$ corresponding correlations were seen with age. 
Citation: Nakeva von Mentzer C, Lyxell B, Sahlén B, Dahlström O, Lindgren M, et al. (2014) The Phonics Approach in Swedish Children using Cochlear Implants or Hearing Aids: Inspecting Phonological Gain. Commun Disord Deaf Stud Hearing Aids 2: 117. doi: $10.4172 / 2375-4427.1000117$

Page 9 of 11

None of these significant correlations were found in children with weak PhPS. One interpretation is that when dealing with phonological processing tasks, complex working memory may contribute differently in the group of DHH children. Some of them may be able to recruit similar cognitive strategies for comprehension, storing and recalling, the way they are measured in the SCR task [41], as when they deal with phonological processing tasks. Thus, they use their executive abilities to shift attention between different aspects of the incoming speech signal $[50,51,62]$. It is therefore important to consider working memory performance in children with HA and CI since it is a robust predictor of many different aspects of language functioning $[19,24,30,63]$. In children with $\mathrm{NH}$ age was the variable with strongest correlations with the phonological composite score [64].

\section{Predictors of phonological gain}

When we examined factors that predicted phonological gain there were different patterns within the groups. In children with $\mathrm{NH}$ only two variables were associated with phonological gain, namely, weak lexical access and letter knowledge. The latter finding replicates neurocognitive studies that have shown that orthographic knowledge shapes the phonological representations involved in spoken language processing $[38,65]$.

For DHH children five variables, all measuring different aspects of phonological and lexical processing were correlated with the phonological gain score. Thus, DHH children who started out at a lower level regarding phonological and lexical abilities benefitted relatively more from the phonics training [17]. When specifically analysing children with weak phonological skills, a positive significant correlation with letter naming appeared. This is in line with the study by Nittrouer et al. [2] that suggest that children's perceptual system might be redirected to visual clues when there is a need to enhance a weak auditory percept. Thus, letter knowledge may function as an intermediate factor, i.e. a driving force to phonological improvement for children with weak initial phonological skills.

Finally, a linear regression analysis revealed that the phonological representation task was the single most important predictor of phonological gain as a function of the phonics training for the whole sample of DHH children; as well as for the DHH children with weak initial phonological processing skills. The phonological representation task captures a wide range of lower level as well as higher level auditory processing and is easy to assess for clinicians working in the field. It may identify children who need to develop PhPS. Additionally the positive outcome of the study is that phonological gain is possible by practicing with computer-based phonics for DHH children.

\section{Limitations of the study}

The DHH population at large is characterized by a high degree of heterogeneity. This was also the case in the present study. That is, although the DHH children shared important features, as all having a sensorineural hearing loss, all using their technical devices continuously and none having any other disability except hearing loss; they differed with respect to several background variables. For example, age at diagnosis, age at amplification, cause and degree of hearing loss and communication mode used at home varied among the children. These variables are worth considering, because they may have affected how the children were able to perform the training, and also how they appreciated the intervention. Consequently, our ambition has been to interpret the data with due caution. That is, to see the empirical pattern as pointing in specific directions rather than making strong causal conclusions. Further, interesting results have been obtained which may in the future; form an inspiration to sharper hypothesis testing. Of special interest would be to disentangle the mechanisms behind the association between letter naming skills and phonological gain.

\section{Conclusions}

DHH children performed at a lower level than $\mathrm{NH}$ children on lexical access and tasks of PhPS but reached comparable levels in complex and visual working memory. The associations between complex working memory and PhPS in DHH children and the lack of such associations in children with $\mathrm{NH}$ may suggest that phonological processing skills require more cognitive resources in the $\mathrm{DHH}$ children. This finding implies that complex working memory capacity in $\mathrm{DHH}$ children should continuously be taken into consideration due to its intimate link to different areas of language processing. Weak performance at pre intervention on the task for Phonological representation was the only significant predictor of phonological gain in DHH children. Children with difficulties with the Phonological representation task were older when diagnosed and had an older age at amplification. Further, these children showed broader cognitive difficulties. For children with weak initial PhPS letter naming was associated with phonological gain. This suggests that for these children, letter knowledge may serve as a driving force to phonological gain.

\section{Acknowledgements}

This research was funded by The Swedish Research Council for Working Life and Social Sciences, the Linneaus Centers HEAD at Linköping University, and CCL-Cognition, Communication and Learning at Lund University. We acknowledge all the children and parents participating in the study and their teachers. We thank Jonas Lindsjö, Lena Asker-Árnason, Lund University, Elisabet Engström, Karolinska University Hospital, and Anna Ericson, Stockholm University for their assistance in the data-collection. We thank UllaBritt Persson, Linköping University for assistance in proofreading.

\section{Conflict of Interest Statement}

No conflict of interest is declared, including financial, personal or other relationships with other people or organizations for any of the authors in this study. All authors have approved the final article.

\section{References}

1. Hickok G (2009) The functional neuroanatomy of language. Phys Life Rev 6: 121-143.

2. Nittrouer S, Caldwell A, Lowenstein JH, Tarr E, Holloman C (2012) Emergent literacy in kindergartners with cochlear implants. Ear Hear 33: 683-697.

3. Wass M, B Lyxell, B Sahlén, L Asker-Arnason, T Ibertsson, et al. (2010) Cognitive skills and reading ability in children with cochlear implants. Cochlear Implants International 11:395-398.

4. Lyxell B, Wass M, Sahlén B, Uhlén I, Samuelsson C, et al. (2011) Development of cognitive and reading skills in deaf children with CIs. Cochlear Implants Int 12 Suppl 1: S98-100.

5. Rodrigues A, Befi-Lopes DM (2009) Phonological working memory and its relationship with language development in children. Pro Fono 21: 63-68. 
Citation: Nakeva von Mentzer C, Lyxell B, Sahlén B, Dahlström O, Lindgren M, et al. (2014) The Phonics Approach in Swedish Children using Cochlear Implants or Hearing Aids: Inspecting Phonological Gain. Commun Disord Deaf Stud Hearing Aids 2: 117. doi: $10.4172 / 2375-4427.1000117$

Page 10 of 11

6. Walley AC, Metsala JL (1990) The growth of lexical constraints on spoken word recognition. Percept Psychophys 47: 267-280.

7. Briscoe J, DV Bishop, CF Norbury(2001) Phonological processing, language, and literacy: a comparison of children with mild-to-moderate sensorineural hearing loss and those with specific language impairment. J Child Psychol Psychiatry 42: 329-340.

8. Geers AE, Moog JS, Biedenstein J, Brenner C, Hayes H (2009) Spoken language scores of children using cochlear implants compared to hearing age-mates at school entry. J Deaf Stud Deaf Educ 14: 371-385.

9. Knight D (2001) Unravelling the relationship between phonological awareness, speech impairment, and literacy. Advances in SpeechLanguage Pathology 3: 149-153.

10. Lyxell B, Sahlén B, Wass M, Ibertsson T, Larsby B, et al. (2008) Cognitive development in children with cochlear implants: relations to reading and communication. Int J Audiol 47 Suppl 2: S47-52.

11. Löfkvist U, Almkvist O, Lyxell B, Tallberg IM (2012) Word fluency performance and strategies in children with cochlear implants: agedependent effects? Scand J Psychol 53: 467-474.

12. Schwartz RG, Steinman S, Ying E, Mystal EY, Houston DM (2013) Language processing in children with cochlear implants: a preliminary report on lexical access for production and comprehension. Clin Linguist Phon 27: 264-277.

13. Beal-Alvarez JS, Lederberg AR, Easterbrooks SR (2012) Graphemephoneme acquisition of deaf preschoolers. J Deaf Stud Deaf Educ 17: 39-60.

14. Trezek BJ, Wang Y (2006) Implications of utilizing a phonics-based reading curriculum with children who are deaf or hard of hearing. J Deaf Stud Deaf Educ 11: 202-213.

15. Trezek BJ, Y Wang (2011) Processes and components of reading, M Marschark and PE Spencer, Editors.

16. Leybaert J, LaSasso CJ (2010) Cued speech for enhancing speech perception and first language development of children with cochlear implants. Trends Amplif 14: 96-112.

17. Nakeva von Mentzer C, B Lyxell, B Sahlén, M Wass, M Lindgren, et al. (2013) Computer-assisted training of phoneme-grapheme correspondence for children who are deaf and hard of hearing: Effects on phonological processing skills. Int J Pediatr Otorhinolaryngol 77: 20492057.

18. Kronenberger WG, Pisoni DB, Henning SC, Colson BG, Hazzard LM (2011) Working memory training for children with cochlear implants: a pilot study. J Speech Lang Hear Res 54: 1182-1196.

19. Beer J, WG Kronenberger, DB Pisoni (2011) Executive function in everyday life: implications for young cochlear implant users. Cochlear Implants Int 12: S89-91.

20. Hansson K, J Forsberg, A Löfqvist, E Mäki-Torkko, B Sahlén (2004) Working memory and novel word learning in children with hearing impairment and children with specific language impairment. Int J Lang Commun Disord 39: 401-422.

21. Ibertsson T, K Hansson, L Asker-Árnason, B Sahlén (2009) Speech recognition, working memory and conversation in children with cochlear implants. Deafness Educ Int 11: 132-151.

22. Lee Y, Yim D, Sim H (2012) Phonological processing skills and its relevance to receptive vocabulary development in children with early cochlear implantation. Int J Pediatr Otorhinolaryngol 76: 1755-1760.

23. Lyxell B, Wass M, Sahlén B, Samuelsson C, Asker-Arnason L, et al. (2009) Cognitive development, reading and prosodic skills in children with cochlear implants. Scand J Psychol 50: 463-474.

24. Pisoni DB, AE Geers (2000) Working memory in deaf children with cochlear implants: correlations between digit span and measures of spoken language processing. Ann Otol Rhinol Laryngol Suppl 185: 92-93.

25. Wass M, T Ibertsson, B Lyxell, B Sahlen, M Hallgren, et al. (2008) Cognitive and linguistic skills in Swedish children with cochlear implants - measures of accuracy and latency as indicators of development. Scand J Psychol 49: 559-576.
26. Willstedt-Svensson U, A Lofqvist, B Almqvist, B.Sahlen (2004) Is age at implant the only factor that counts? The influence of working memory on lexical and grammatical development in children with cochlear implants. Int J Audiol 43: 506-515.

27. Fitzpatrick EM, L Crawford, A Ni, A Durieux-Smith (2011) A descriptive analysis of language and speech skills in 4- to 5-yr-old children with hearing loss. Ear Hear 32: 605-616.

28. Fitzpatrick EM, J Olds, I Gaboury, R McCrae, D Schramm, et al. (2012) Comparison of outcomes in children with hearing aids and cochlear implants. Cochlear Implants Int 13: 5-15.

29. Stiles DJ, RA Bentler, KK McGregor (2012) The Speech Intelligibility Index and the pure-tone average as predictors of lexical ability in children fit with hearing AIDS. J Speech Lang Hear Res 55: 764-778.

30. Pisoni DB, M Cleary (2003) Measures of working memory span and verbal rehearsal speed in deaf children after cochlear implantation. Ear Hear 24: 106S-20S

31. Fu QJ, G. Nogaki (2005) Noise susceptibility of cochlear implant users: the role of spectral resolution and smearing. J Assoc Res Otolaryngol 6: 19-27.

32. Bouton S, W Serniclaes, J Bertoncini, P Cole (2012) Perception of speech features by French-speaking children with cochlear implants. Journal of speech, language, and hearing research : JSLHR 55: 139-153.

33. Moore BC (2008) The role of temporal fine structure processing in pitch perception, masking, and speech perception for normal-hearing and hearing-impaired people. J Assoc Res Otolaryngol 9: 399-406.

34. Caldwell A, S Nittrouer (2013) Speech perception in noise by children with cochlear implants. J Speech Lang Hear Res 56: 13-30.

35. Sharma A, MF Dorman, AJ Spahr (2002) A sensitive period for the development of the central auditory system in children with cochlear implants: implications for age of implantation. Ear Hear 23: 532-539.

36. Lyytinen H, J Erskine, J Kujala, E Ojanen, U Richardson (2009) In search of a science-based application: a learning tool for reading acquisition. Scandinavian Journal of Psychology 50: 668-675.

37. Lyytinen H, M Ronimus, A Alanko, AM Poikkeus, M Taanila (2007) Early identification of dyslexia and the use of computer game-based practice to support reading acquisition. Nordic Psychology 59: 109-126.

38. Brennan C, F Cao, N Pedroarena-Leal, C McNorgan, JR Booth (2012) Reading acquisition reorganizes the phonological awareness network only in alphabetic writing systems. Hum Brain Mapp.

39. Baddeley A (2012) Working memory: theories, models, and controversies. Annu Rev Psychol 63: 1-29.

40. Baddeley A, G Hitch (1974) Working memory in The psychology of learning and motivation: Advances in research and theory. GH Bower, Editor, New York: Academic Press, 47-89.

41. Just MA, PA Carpenter (1992) A capacity theory of comprehension: individual differences in working memory. Psychol Rev 99: 122-149.

42. Bishop DVM (1997) Uncommon understanding: Development and disorders of language comprehension in children. Hove, England: Psychology Press/Erlbaum (UK): Taylor \& Francis, 277.

43. Gerken LA (1994) Young children's representations of prosodic phonology: evidence from English-speakers' weak syllable productions. Journal of Memory and Language 33: 19-38.

44. Leonard LB (2000) Children with specific language impairment. Cambridge, Massachusetts, London, England: A Bradford Book, The MIT Press.

45. Kamhi AG, HW Catts (1986) Toward an understanding of developmental language and reading disorders. The Journal of Speech and Hearing disorders 51: 337-347.

46. Sahlén B, C Reuterskiöld-Wagner, U Nettelbladt, K Radeborg (1999) Non-word repetition in children with language impairment--pitfalls and possibilities. Int J Lang Commun Disord 34: 337-352.

47. Hellquist B (1995) Lilla Fonemtestet Malmö: Pedagogisk Design.

48. Frylmark A (1995) Språkundersökning på BVC och hos logoped inför skolstart, in Stockholm: Socialstyrelsen. 96-144.

49. Clay M (1975) Early detection of reading difficulties: A diagnostic survey. 
Citation: Nakeva von Mentzer C, Lyxell B, Sahlén B, Dahlström O, Lindgren M, et al. (2014) The Phonics Approach in Swedish Children using Cochlear Implants or Hearing Aids: Inspecting Phonological Gain. Commun Disord Deaf Stud Hearing Aids 2: 117. doi: $10.4172 / 2375-4427.1000117$

Page 11 of 11

50. Baddeley A (2000) The episodic buffer: a new component of working memory? Trends Cogn Sci 4: 417-423.

51. Repovs G, A Baddeley (2006) The multi-component model of working memory: explorations in experimental cognitive psychology. Neuroscience 139: 5-21

52. Dillon CM, DB Pisoni (2006) Nonword repetition and reading in children who are deaf and have cochlear implants. International Congress Series 1273: 304-307.

53. Gathercole SE (2006) Nonword repetition and word learning: The nature of the relationship. Applied Psycholinguistics 27: 513-543.

54. Nettelbladt, U, K Salameh (2007) Språkstörning hos barn. Språkutveckling och språkstörning. Del 1. Fonologi, grammatik och lexikon, 13, Lund: Studentlitteratur.

55. Brem S, S Bach, K Kucian, TK Guttorm, E Martin, et al. (2010) Brain sensitivity to print emerges when children learn letter-speech sound correspondences. Proc Natl Acad Sci U S A 107: 7939-7944.

56. Kyle F, J Kujala, U Richardson, H Lyytinen, U Goswami (2013) Assessing the Effectiveness of Two Theoretically Motivated Computer- Assisted Reading Interventions in the United Kingdom: GG Rime and GG Phoneme. Reading Research Quarterly 48: 61-76.

57. Nakeva von Mentzer C, B Lyxell, B Sahlén, Ö Dahlström, M Lindgren, et al. (2014) Computer assisted reading intervention with a phonics approach for children using cochlear implants or hearing aids.Scand J Psychol 55: 448-455.
58. Baddeley A, S Gathercole, C Papagno (1998) The phonological loop as a language learning device. Psychol Rev 105: 158-173.

59. James D, K Rajput, J Brinton, U Goswami (2008) Phonological awareness, vocabulary, and word reading in children who use cochlear implants: does age of implantation explain individual variability in performance outcomes and growth? J Deaf Stud Deaf Educ 13: 117-137.

60. Sininger YS, A Grimes, E Christensen (2010) Auditory development in early amplified children: factors influencing auditory-based communication outcomes in children with hearing loss. Ear Hear 31: 166-185.

61. Kronenberger WG, J Beer, I Castellanos, DB Pisoni, RT Miyamoto (2014) Neurocognitive risk in children with cochlear implants. JAMA Otolaryngol Head Neck Surg 140: 608-615.

62. Magimairaj BM, JW Montgomery (2012) Children's verbal working memory: relative importance of storage, general processing speed, and domain-general controlled attention. Acta Psychol (Amst) 140: 196-207.

63. Berninger VW, RD Abbott, W Nagy, J Carlisle (2010) Growth in phonological, orthographic, and morphological awareness in grades 1 to 6. J Psycholinguist Res 39: 141-163.

64. Snowling M, C Hulme (1994) The development of phonological skills. Philos Trans R Soc Lond B Biol Sci 346: 21-27.

65. Perre L, C Pattamadilok, M Montant, JC Ziegler (2009) Orthographic effects in spoken language: on-line activation or phonological restructuring? Brain Res 1275: 73-80. 